\title{
Could the candidate causal gene (LZTFL1) identified by Oxford University scientists, which doubles the risk of COVID-19-related respiratory failure, be used to boost the Weak immunogenicity of COVID-19 mRNA vaccines in patients with B-cell chronic lymphocytic leukemia (CLL)???. A double edged sword
}

Mahmoud Ramadan Elkazzaz ( $\square$ mahmoudramadan2051@yahoo.com )

Department of chemistry and biochemistry, Faculty of Science, Damietta University, Egypt https://orcid.org/0000-0003-3703-520X

Yousry Esam-Eldin Abo-Amer ( $\sim$ dryousryaboaamer@hotmail.com )

Hepatology,Gastroenterology and Infectious Diseases Department, Mahala Hepatology Teaching Hospital, Egypt https://orcid.org/0000-0002-6136-8840

Tamer Haydara ( $\square$ tamerhaydara@yahoo.com )

Faculty of Medicine, Kafrelsheikh University, Egypt

Aziz Rodan Sarohan ( $\square$ azizrodan@gmail.com )

Department of Obstetrics and Gynecology, Medicina Plus Medical Center, 75. Yıl Mah., İstiklal Cad. 1305 Sk., No: 16 Sultangazi, İstanbul, Turkey https://orcid.org/0000-0002-5794-688X

Amr Ahmed

Director of tuberculosis program Ghubera, public health department ,First health cluster ,Ministry of health , Riyadh, Saudia Arabia https://orcid.org/0000-0003-3477-236X

Method Article

Keywords: Haematological malignancies, mRNA COVID-19 vaccine, LZTFL1 gene, All trans retinoic Acid, CD4 T cells, Lung

Posted Date: December 7th, 2021

DOl: https://doi.org/10.21203/rs.3.rs-1079599/v4

License: (c) (1) This work is licensed under a Creative Commons Attribution 4.0 International License. Read Full License 


\section{Abstract}

Patients with B-cell chronic lymphocytic leukemia (CLL) have an increased risk of severe infections due to disease- and treatment-related immunodeficiency. As a result, patients with hematologic malignancies have been given priority for primary COVID-19 vaccination. Unfortunately, many studies have suggested that patients with B-cell chronic lymphocytic leukemia (CLL) who have been fully vaccinated can develop severe and often fatal complications. Therefore, adjuvants that can induce mRNA vaccine efficacy are desperately needed for this category of patients with haematological malignancies. A recent, study by Oxford University scientists showed that leucine zipper transcription factor-like 1(LZTFL1), as a candidate causal gene and its enhancer the rs17713054 A risk allele was significantly responsible for the twofold increased risk of respiratory failure from COVID-19 associated with 3p21.31.By using sequence analysis, the risk allele generates a second CCAAT/enhancer binding protein beta (CEBPB) motif in the enhancer. Moreover, neither LZTFL1 variants found in T cells nor B cells are responsible for increasing death risk from COVID-19 infection according to oxford study. Here, we propose attestable hypothesis that trans retinoic acid could enhance the immune response in vaccinated patients with B-cell chronic lymphocytic leukemia (CLL) according to the recent findings of Oxford scientists by inducing the casual gene(LZTFL1) in CD4 T cells and inhibiting (CEBPB) motif.

\section{Conclusions}

Haematological malignancies (blood cancers) patients are more vulnerable to COVID-19 disuse severity and mortality. Un fortunately mRNA vaccine seem to be less effective with weak immune response and insufficient level of generated antibodies in this category of patients. Therefore we suggest all trans retinoic acid is a good candidate as mRNA COVID-19 vaccine adjuvant via inducing LZTFL1 gene in CD4Tcells and this activation could improve the immune response and increase the level of the generated antibodies. Moreover LZTFL1 gene in CD4 T cells is not associated with increasing risk of COVID-19 infection because of absence of its enhancer(The risk allele of the SNP, rs17713054 A) in immune cells according to oxford recent study. In addition to all trans retinoic acid could inhibit CCAAT/enhancer binding protein beta motif that is generated by The risk allele of the SNP, rs17713054 A

\section{Introduction}

The COVID-19 pandemic is estimated to have caused over 4.6 million deaths so far $(1,2)$. The leading cause of mortality is severe acute respiratory distress syndrome and pneumonia (3). Cancer is a risk factor for a more aggressive clinical course in COVID-19 patients. In a previous report, it was reported that 39 percent of COVID-19 patients with cancer had severe events such as intensive care unit (ICU) admission, need for mechanical ventilation (MV), and death during the COVID-19 course, whereas only 8 percent of COVID-19 patients without cancer had those severe events. Patients with haematological 
malignancies may be more vulnerable than patients with solid tumors due to immune system dysfunction $(4,5)$. The poor prognosis and worse outcomes in hematologic malignancies patients following infection with the severe acute respiratory syndrome coronavirus-2 SARS-CoV-2) is now well documented. A recent published meta-analysis, conducted on 3377 patients with hematologic malignancies, found a $34 \%$ risk of mortality in those suffering from COVID-19 (6). It was found that found that $77 \%$ of consecutive CLL patients diagnosed with Covid-19 developed severe disease requiring hospitalization, and of these $28 \%$ died from Covid- 19 and its complications(7). Moreover, immunotherapy that depletes B-cell has been linked to higher rate of death and prolonged hospitalization following COVID19 (7) . As a result, patients with hematologic malignancies have been given priority for primary COVID-19 vaccination. Several COVID-19 vaccines became available in 2020 and 2021, according to several randomized clinical studies. In Europe and the United States, ChAdOx1 nCoV-19, Pfizer/BioNTech, and mRNA-1273 (Moderna) vaccines are available $(8,9,10)$. Those with hematologic malignancies, however, were not included in these vaccine clinical trials. SARS-CoV-2 IgG production was measured in 67 hematologic malignancies patients who received two mRNA vaccine doses, and it was discovered that $46 \%$ of hematologic malignancies patients did not produce antibodies, indicating that they were vaccine non-responders(11). Patients with B-cell CLL were especially vulnerable, as only $23 \%$ of them had detectable antibodies despite the fact that nearly $70 \%$ of them were not receiving cancer treatment (11). Preliminary studies in patients with hematologic malignancies found a low seroconversion rate after the first BNT162b2 inoculum, ranging from 18 to $25 \%(12,13)$. These findings contrast sharply with the findings of a phase 1 mRNA vaccine immunogenicity trial, which reported robust antibody responses in nearly all healthy volunteers after two injections of $30 \mathrm{~g}$ of BNT162b2 $(14,15,16)$. In patients with haematological malignancies such multiple myeloma and non-Hodgkin lymphoma (lymphoid and myeloid malignancy) as, vaccination with two BNT162b2 inocula results in a significant increase in cellular response and humoral, but only about half of the patients will likely achieve effective immune protection against COVID-19(17). Immunosuppression is frequently associated with hematologic malignancies, and the treatment used can exacerbate the immune defect, raising the question of vaccine immunogenicity in those patients(17). Anti-CD20 monoclonal antibodies and other B-cell targeting treatments, such as immunomodulatory drugs, proteasome inhibitors, steroids or antiCD38 monoclonal antibodies used in multiple myeloma treatment, may impair COVID-19 neutralizing antibody production after vaccination(17). Patients receiving venetoclax and BTKis anti-CD20 were unlikely to respond to vaccination. It is not surprising that BTKis impair the humoral response to vaccination because they block B-cell receptor signalling in both malignant and normal B cells. Previous research has reported antibody-mediated response rates to influenza vaccine ranging from $7 \%$ to $26 \%$ in CLL patients treated with BTKis(18). In fact, B-cell depleting agents and glucocorticoids have been shown to significantly reduce the immunogenicity of mRNA vaccines against COVID19 in patients with chronic inflammatory disease (19). Here we propose a testable hypothesis that The drugs that induce the expression of Leucine zipper transcription factor-like 1 (LZTFL1) gene in CD4 T cells could be used in boosting the weak immunogenicity of COVID-19 mRNA vaccines in patients with hematologic malignancy via activating T cells. LZTFL1 (leucine zipper transcription factor-like 1) was discovered as a tumour suppressor for the first time(20). LZTFL1 is encoded by a gene on human chromosome (3p21.3 
)that has been showed to be deleted in a many types cancers (20). Overexpression of LZTFL1 in HeLa cells, a cervical cancer cell line, inhibited anchorage-independent cell migration and growth in vitro and inhibited growth of tumour in vivo (21). LZTFL1 was found to be expressed highly in the epithelial cells of normal tissues and is significantly down regulated in the corresponding tumor samples (22). Loss of LZTFL1 expression was found to have significant inverse correlations with TNM (tumor (T), node $(\mathrm{N})$, and metastasis $(\mathrm{M})$ ) stages of the tumor and with the number of metastasized lymph nodes $(\mathrm{mLN})$ (23). Recently, a deletion mutant of LZTFL1 was also found in a family with Bardet-Biedl syndrome (BBS)(24), Leucine zipper transcription factor like 1 (Lztfl1)/BBS17 is a member of the Bardet-Biedl syndrome (BBS) gene family. Human BBS patients have a wide range of pathologies including obesity $(24,25)$. Recently, LZTFL1 knockout mice was well established, which showed the phenotype of obesity, retinal degeneration, and abnormal cilia development $(26,27,28)$.

A recent study by Oxford University scientists was published in Nature genetic ( Nat Genet 53, 1606-1615 (2021). https://doi.org/10.1038/s41588-021-00955-3) showed that leucine zipper transcription factorlike 1(LZTFL1), as a candidate causal gene and its enhancer the rs17713054 A risk allele was significantly responsible for the twofold increased risk of respiratory failure from COVID-19 associated with 3p21.31(29). LZTFL1 is widely expressed in pulmonary epithelial cells, including ciliated epithelial cells, which have been identified as one of the main cellular targets for SARS-CoV-2 infection. The scientists in this study used a combined multiomics and machine learning approach and identified that the gain-of-function risk $A$ allele of an SNP, rs17713054G>A, was a causative variant. By using chromosome conformation capture and gene-expression analysis oxford scientists showed that the rs17713054-affected enhancer upregulates the interacting gene, leucine zipper transcription factor like 1 (LZTFL1). The risk allele of the SNP, rs17713054 A, leads to increased transcription through augmentation of an epithelial-endothelial-fibroblast enhancer, facilitated by the addition of a second CEBPB binding motif. Sequence analysis showed that the risk allele generates a second CCAAT/enhancer binding protein beta (CEBPB) motif(57) in the enhancer. Therefore, according to this study the rs17713054 risk allele must generate a CCAAT/enhancer binding protein beta motif to increase covdid19 risk via interacting with LZTFL1. The strong expression of CEBPB in lung tissue supports the biological relevance of this new motif ( 64) and chromatin immunoprecipitation supported by sequencing (ChIP-seq) of CEBPB in lung fibroblast cells of IMR-90 and HeLa, A549 alveolar basal epithelial adenocarcinoma (65). Moreover, deepHaem predicted that rs17713054-A would resulted in induced binding of CEBPB in A549 cells and IMR-90 (29). This study found that rs17713054is an active enhancer of LZTFL1 in lungs and associated with increased risk of COVID-19 and is not in an active enhancer in immune cells, where CCR9 is expressed. The 3p21.31-related risk is most likely caused by pulmonary epithelial cells undergoing EMT, rather than immune cells, according to this study. LZTFL1 could be a therapeutic target because the 3p21.31 effect is conferred by a gain-of-function (29). LZTFL1 variants that induce risk of severe COVID-19 disease is not found in immune cells as in this study they first examined open chromatin from 24 diverse immune cell populations (including T, B, natural killer and dendritic cells) in resting and stimulated states but did not identify any of the 28 severe COVID-19associated variants of LZTFL1 at 3p21.31 in open chromatin making it unlikely that a cis-regulatory 
mechanism in these immune cell types is responsible for COVID-19 risk. These results concluded that neither LZTFL1 variants found in T cells nor B cells are responsible for increasing death risk from COVID-19 infection. Therefore the expression of LZTFL1 in immune cells is not a risk factor for COVID-19 severity and its enhancer ). The risk allele of the SNP, rs17713054 A is not expressed in these cells as found in $60 \%$ of individuals with South Asian ancestry (SAS), compared to $15 \%$ of European ancestry (EUR) groups. Fortunately, LZTFL1 was discovered to potentially activate CD4 T cells under the control of All trans retinoic acid (ATRA), ATRA induces LZTFL1 expression in human primary CD4+ T cells $(30,31,61)$. We searched literature using PubMed, Google Scholar, Preprints , Clinical trials and letters and found only ATRA could induce LZTFL1 in CD4 T cell and not in other tissues. LZTFL1 is a putative transcription factor with a leucine zipper domain and is a part of a transcriptional map that includes the CCR9 gene(20). CCR9 mediates chemotaxis in response to CCL25/thymus-expressed chemokine and is selectively expressed on T cells in the thymus and small intestine(62). Retinoic acid can induce the expression of the $\mathrm{G}$ protein coupled chemokine receptor 9 (CCR9) on lymphocytes, which allows their migration toward the GIT that expresses the chemokine ligand CCL25(63) In addition to all trans retinoic acid was found to potentially downregulate EBP $\beta(C C A A T /$ enhancer binding protein beta motif), exposure of Hepa-1 cells to Retinoic Acid results in a decrease in C/EBP $\beta$ mRNA levels(55). Retinoic acid prevented C/EBPb-induced adipocyte differentiation and C/EBPbeta-mediated transcription(56). In transient transfection studies, liganded RA receptor (RAR) specifically blocks transcriptional activation by either $\mathrm{C} / \mathrm{EBPa}$ or $\mathrm{C} / \mathrm{EBPb}(56)$. RA completely prevented $\mathrm{C} / \mathrm{EBPb}$-induced adipogenesis(56). RA does not act directly on $\mathrm{C} / \mathrm{EBP} \beta$ but rather stimulates the expression of the transforming growth factor $\beta$-effector protein Smad3, which can interact with C/EBP $\beta$ via its Mad homology 1 domain and can interfere with $\mathrm{C} / \mathrm{EBP} \beta$ DNA binding(57). The RA-induced increase in Smad3 expression results in increased cytoplasmic and nuclear Smad3, which is significant because ectopic Smad3 expression in preadipocytes in the absence of RA treatment only modestly inhibits adipogenesis and C/EBP DNA binding, implying that Smad3 alone is insufficient to fully recapitulate the effects of retinoic acid treatment during differentiation(57). Smad3 signaling is crucial for progression to fibrosis. On the other hand, absence of proper Smad3 signaling results in an ineffective repair response to damage in the lung, reduction of suppression of expression of potent MMPs, and susceptibility to airspace enlargement and emphysema(64). Retinoic acid (RA) is a potent inhibitor of adipogenesis, and its action appears to block C/EBP $\beta$ transcriptional potential early during differentiation(57). Therefore, ATRA could have a beneficial impact in treating patients which have the risk allele of the SNP, rs17713054 A via inhibiting EBP $\beta$ (CCAAT/enhancer binding protein beta motif). Moreover, all trans retinoic acid could boost $\mathrm{T}$ cell activity and immune response in vaccine non-responder patients with hematopoietic malignancy by inducing LZTFL1 in CD4 T cells, according to these findings. T cell function is influenced by RAs in a variety of ways, including peripheral T cell differentiation, gut-homing capacity, and effector T cell activity(46-51). In Ab-primed human PBMCs, RAs promote Th2 cell differentiation and can directly induce the production of Th2 cytokines IL-5, IL-4, and IL-13(32). LZTFL1 has been identified as a critical regulator of ATRA-induced Th2 cytokine expression in CD4+ T cells, particularly expression of Interleukin -5 (30). At physiological concentrations of ATRA., LZTFL1 was rapidly and markedly upregulated in primed CD4+ T cells (30). It is believed that LZTFL1 is a positive regulator of ATRA-induced T cell 
response because it is upregulated by ATRA in activated T cells (30). ATRA treatment increases LZTFL1 mRNA and protein production in human CD4+ T cells(30). LZTFL1 transiently localizes to the immunological synapse during CD4+ T cell activation in contact with APC (IS). The T cell activation signal was further enhanced by overexpression of LZTFL1 in CD4+ T cells, as evidenced by increased NFAT activity. Furthermore, knocking down LZTFL1 reduced Th2 cytokine production, particularly IL-5 mRNA and protein, and suppressed ATRA-induced IL-5 production.(30). It was showed that SARS-CoV-2 mRNA vaccines induce broad CD4+ T cell responses that recognize SARS-CoV-2 variants and HCoVNL63, (33).SARS-CoV-2 and common cold coronaviruses (CCCs) have recently been shown to crossrecognize T cells (34-43). The mRNA COVID-19 vaccines from Moderna (mRNA-1273) and PfizerBioNTech (BNT162b2) produce strong T cell responses to spike peptides $(44,45)$.All trans Retinoic acid could enhance the efficacy of these mRNA COVID-19 vaccine via inducing LZTFL1. On activated T and B lymphocytes, retinoic acid (RA), a Vitamin A metabolite, was found to upregulate the mucosal homing receptors CCR9 and integrin alpha4beta7 $(52,53)$. Infection and mucosal vaccination require RA to elicit proinflammatory CD4+ helper $T$ cell responses. These effects are mediated by the retinoic acid receptor alpha (RAR). RAR signalling antagonistism and RAR(Rara/) deficiency result in a cell autonomous CD4+ $T$ cell activation defect. Overall, these findings establish nutritional status as a broad regulator of adaptive $T$ cell responses and reveal a critical role for the RA/RAR axis in the development of both regulatory and inflammatory arms of adaptive immunity(54). The retinoic acid-mediated regulation of a4 integrins is required for specific migration of T cells in vitro and in vivo(31). RA promotes the generation of small intestine-homing $T$ and $B$ cells $(48,53)$. In this regard, a severe paucity of $T$ cells and IgAproducing $B$ cells occurs in the intestine of vitamin A deficiency. These functions of RA are consistent with the increased susceptibility of vitamin A deficient subjects to a number of infectious microbial agents(62).Retinoic acid specifically induces the expression of a small intestine-homing chemokine receptor CCR9 and a mucosal tissue-homing integrin molecule a4ß37(48). All trans retinoic acid could increase COVID-19 vaccine protective effect as All trans retinoic acid was found to increase IgA production and that this was a result of its ability to increase the frequency of IgA-secreting $B$ cell clones(61). Therefore, it is not surprising that ATRA exhibited antiviral effect against SARS-CoV-2 3 CLpro cell culture (58) In addition to retinoic acid was found to protect against COVID-19 disease severity $(59,60)$.

\section{Study Description}

This double blinded, randomized, placebo controlled trial on the clinical efficacy ALL trans Retinoic Acid as an adjuvant mRNA covid-19 vaccine. 25 men and women with hematological malignancy will be enrolled, who are age 18 to 65 years inclusive, have given informed consent to participate in the study. All of the enrollees will not have active COVID-19. All-trans retinoic acid (ATRA) has an immunomodulatory effect on haemopoiesis, making it a possible option for inducing COVID-19 vaccine efficacy. The effect of all trans retinoic acid on the efficacy and the immune response of mRNA covid-19 vaccine status will be examined in the context of a randomized trial conducted in Egyptian or Saudi Arabian Subjects will be randomized to receive either mRNA COVID-19 vaccine combined with doses of 
all trans retinoic acid or placebo from the start of their first dose of vaccination, and until the last recruited patient reaches its last mRNA covid-19 vaccine dose and 6 months of follow up. Thus, the first subject is likely to be followed for 12 months, assuming the duration of recruitment is 12 months. The endpoints of interest include, immune response to mRNA covid-19 vaccine. The study will be carried out as a collaborative effort between. Kafr elshiekh university ,Faculty of Medicine, Egypt and First health cluster ,Ministry of health ,Saudia Arabia. All enrolled patients in the active cooperator with hematological malignancy will be randomly assigned to receive 2 shot of BNT162b2 mRNA vaccine(Administration of BNT162 b2 vaccine $(30 \mu \mathrm{g}$ in $0.3 \mathrm{~mL})$ at D1 and D29, intramuscularly (participants without antecedent of SARS-CoV-2 infection) in combination with oral ATRA (10 mg twice daily . ATRA will be given orally after the first vaccine shot for 10 days and also it will be given orally after the second vaccine shot for 10 days and the investigators will check the efficacy and safety of this combination in the enrolled population .

\section{Materials And Methods}

Active Comparator: Oral All trans retinoic acid plus BNT162 b2 vaccine

12 subjects will be randomly assigned to receive 2 shot of BNT162b2 mRNA vaccine(Administration of BNT162 b2 vaccine $(30 \mu \mathrm{g}$ in $0.3 \mathrm{~mL})$ at D1 and D29, intramuscularly (participants without antecedent of SARS-CoV-2 infection) in combination with oral ATRA (10 mg twice daily. ATRA will be given orally after the first vaccine shot for 10 days and also it will be given orally after the second vaccine shot for 10 days and the investigators will check the efficacy and safety of this combination in the enrolled population 4

Placebo Comparator: BNT162 b2 vaccine

12 subjects will be randomly assigned to receive 2 shot of BNT162b2 mRNA vaccine(Administration of BNT162 b2 vaccine $(30 \mu \mathrm{g}$ in $0.3 \mathrm{~mL})$ at D1 and D29, intramuscularly (participants without antecedent of SARS-CoV-2 infection)

Anticipated Results and Measurements outcomes

Primary Outcome Measure: 
1-IgG humoral response to vaccine 28 days post vaccination

[ Time Frame: at Day 57 for patients of the group1 and at Day 29 for patient of the group 2 ]

2- Anti SARS-CoV-2 Spike IgG (ELISA test) 28 days after the last injection i.e. at Day 57 in adult volunteers receiving 2 vaccine doses plus oral All trans retinoic acid(group 1, without documented history of SARSCoV-2 infection) and at Day 29 in adult volunteers receiving 1 vaccine dose (group 1, without documented history of SARS-CoV-2 infection).

Secondary Outcome Measures:

1. Humoral response to vaccine plus ATRA vs placebo [ Time Frame: Day 1, Day 29, Day 57, Month 6 , Month 12, Month 24 ]

Anti SARS-CoV-2 specific IgG at Day 1, Day 28, Day 57 , as measured via ELISA Anti SARS-CoV-2 IgA and IgM (total and subclasses IgG 1-4) as measured by ELISA at D 1, D28, D56, M6, M12 and M24 Specific neutralizing antibody to SARS-CoV-2 and its variants (classical in vitro neutralisation assay and Pseudo neutralisation assay ) (all participants)

1. T cells response to vaccine plus ATRA vs placebo [ Time Frame: at Day1, Day 56 and Month 6 ] Fluorospot assays (TH1, TH2, TH17, Cytotoxicity) Phenotyping of antigen specific T-Cells via Mass cytometry at D 1 and M6 selected from results of Fluorospot assay

1. Mucosal response to vaccine plus ATRA vs placebo [ Time Frame: at Day 1, Day 28, Day 56, Month 6, Month 12 and Month 24 ]

Mucosal COVID-19 -specific antibody via measure of IgA, IgM and IgG in saliva by specific home-made and commercially available ELISA assays for salivary IgA and IgG (all participants)

1. B cell response to vaccine plus ATRA vs placebo [ Time Frame: at Day 1, Day 56 and Month 12 ]

Determination of the epitope profiling and B cell repertoire (stereotype clonotype) of the humoral response 
2. predictive determinants of vaccine plus ATRA response [ Time Frame: at screening visit ]

Pre-existing serology for COVID-19 or other coronavirus, clinical profile of COVID 19 , immune cell phenotype immunosenescence profile, and transcriptomic analysis.

3. Safety of BNT162b2 vaccine plus ATRA [ Time Frame: through 28 days after each dose of vaccine for reactions; throughout the study period for others adverse events ]

All grade adverse reactions:

- Local and systemic reactogenicity, all grade, measured by solicited adverse reactions

- Immediate reactogenicity defined as any adverse reactions

- Unsolicited adverse reactions

Others adverse events:

- Medically significant AEs

- SAEs

- Any AEs of grade $\geq 2$, .

- AEs leading to withdrawal .

Criteria

Inclusion Criteria

- Any patient diagnosed with hematological malignancy

(CLL or B-cell CLL was according to the IWCLL criteria

- Male or female participants $\geq 65$ years of age at the time of consent

Exclusion Criteria:

- History of severe adverse reaction associated with a vaccine and/or severe allergic reaction (eg, anaphylaxis)

- Serious chronic disorder that in the investigator's opinion would make the participant inappropriate for entry into the study

- Previous clinical or microbiological diagnosis of COVID-19

- Previous vaccination with any investigational pneumococcal vaccine, or planned receipt of any licensed or investigational pneumococcal vaccine through study participation 
- Previous vaccination with any coronavirus vaccine.

- Other medical or psychiatric condition including recent (within the past year) or active suicidal ideation/behavior or laboratory abnormality that may increase the risk of study participation or, in the investigator's judgment, make the participant inappropriate for the study

- Hypercholesterolemia

- Hypertriglyceridemia

- Liver disease

- Renal disease

- Sjögren syndrome

- Pregnancy

- Lactation

- Depressive disorder

- Body mass index less than 18 points or higher than 25 points

- Contraindications for hormonal contraception or intrauterine device.

- Autoimmune diseases A history of organ, bone marrow or hematopoietic stem cell transplantation

- Patients receiving anti-hcv treatment

- Permanent blindness in one eye

- History of iritis, endophthalmitis, scleral inflammation or retinitis 15-90 days of retinal detachment or eye surgery

- 16-The competent physician considered it inappropriate to participate in the study

\section{Declarations}

\section{ETHICAL CONCIDERATION}

- Before conducting present study, the approval of the ethics committee and the research council of Both Kafr-Elshiekh university ,Faculty of Medicine and National committee of Bioethics (H-01-R-009), Riyadh, Saudia Arabia. Written consent will be taken from the study participants (Patients \& control) after explaining the aim of the study to them. . All research steps will be recorded in IRCT. - Written consent is obtained from all patients before entering the study. $\cdot$ We will provide patients with complete and clear information about the research process. At each phase of the study, patients are allowed to leave the study. $\cdot$ The medical record of all patients are fully preserved

\section{Conflict of Interest Statement}

The author declares that the research was conducted in the absence of any commercial or financial relationships that could be construed as a potential conflict of interest 


\section{References}

1-Zhu, N. et al. A novel coronavirus from patients with pneumonia in China, 2019. N. Engl. J. Med. 382, 727-733 (2020).

2-Dong, E., Du, H. \& Gardner, L. An interactive web-based dashboard to track COVID-19 in real time. Lancet Infect. Dis. 20, 533-534 (2020).

3-Marini, J. J., Hotchkiss, J. R. \& Broccard, A. F. Bench-to-bedside review: microvascular and airspace linkage in ventilator-induced lung injury. Crit. Care 7, 435-444 (2003).

4-. Liang W, Guan W, Chen R, et al. Cancer patients in SARS-CoV-2 infection: a nationwide analysis in China. Lancet Oncol. 2020 Mar;21(3):335-337.

5-. FDA. Investigational covid-19 convalescent plasma-emergency INDs. https://www.fda. gov/ vaccinesblood-biologics/investigational-new-drug-ind-ordevice-exemption-ideprocess-cber/investigational-covid19-convalescent-plasmaemergency-inds. (Accessed May 11. 2020).

6-Vijenthira A, Gong IY, Fox TA, Booth S, Cook G, Fattizzo B, et al. Outcomes of patients with hematologic malignancies and COVID-19: a systematic review and meta-analysis of 3377 patients. Blood. 2020;136:2881-92.

7- Blixt, L., Bogdanovic, G., Buggert, M. et al. Covid-19 in patients with chronic lymphocytic leukemia: clinical outcome and B- and T-cell immunity during 13 months in consecutive patients. Leukemia (2021). https://doi.org/10.1038/s41375-021-01424-w

8-Polack FP, Thomas SJ, Kitchin N, Absalon J, Gurtman A, Lockhart S, et al. Safety and efficacy of the BNT162b2 mRNA Covid-19 vaccine. N Engl J Med. 2020;383:2603-15.

9-Ramasamy MN, Minassian AM, Ewer KJ, Flaxman AL, Folegatti PM, Owens DR, et al. Safety and immunogenicity of ChAdOx1 nCoV-19 vaccine administered in a prime-boost regimen in young and old adults (COV002): a single-blind, randomised, controlled, phase 2/3 trial. Lancet (London, England). 2021;396:1979-93. 
10-Baden LR, El Sahly HM, Essink B, Kotloff K, Frey S, Novak R, et al. Efficacy and safety of the mRNA1273 SARS-CoV-2 vaccine. N Engl J Med. 2021;384:403-16.

11-Agha M, Blake M, Chilleo C, Wells A, Haidar G. Suboptimal response to COVID-19 mRNA vaccines in hematologic malignancies patients. medRxiv [Preprint]. 2021 Apr 7:2021.04.06.21254949. doi: 10.1101/2021.04.06.21254949. PMID: 33851182; PMCID: PMC8043479.

12-Monin L, Laing AG, Muñoz-Ruiz M, McKenzie DR, Del Molino Del Barrio I, Alaguthurai T, et al. Safety and immunogenicity of one versus two doses of the COVID-19 vaccine BNT162b2 for patients with cancer: interim analysis of a prospective observational study. Lancet Oncol. 2021;22:765-78.

13-Terpos E, Trougakos IP, Gavriatopoulou M, Papassotiriou I, Sklirou AD, Ntanasis-Stathopoulos I, et al. Low neutralizing antibody responses against SARS-CoV-2 in elderly myeloma patients after the first BNT162b2 vaccine dose. Blood. 2021;137:3674-6.

14-Walsh EE, Frenck RW Jr, Falsey AR, Kitchin N, Absalon J, Gurtman A, et al. Safety and immunogenicity of two RNA-based Covid-19 vaccine candidates. N Engl J Med. 2020;383:2439-50.

15-Jackson LA, Anderson EJ, Rouphael NG, et al. An mRNA Vaccine against SARS-CoV-2 - Preliminary Report. N Engl J Med. 2020;383(20):1920-1931

16-Mulligan MJ, Lyke KE, Kitchin N, et al. Phase I/II study of COVID-19 RNA vaccine BNT162b1 in adults. Nature. 2020;586(7830):589-593

17-Malard, F., Gaugler, B., Gozlan, J. et al. Weak immunogenicity of SARS-CoV-2 vaccine in patients with hematologic malignancies. Blood Cancer J. 11, 142 (2021). https://doi.org/10.1038/s41408-021-00534-z

18-65-Douglas AP, Trubiano JA, Barr I, Leung V, Slavin MA, Tam CS. Ibrutinib may impair serological responses to influenza vaccination. Haematologica. 2017 Oct;102(10):e397-e399. doi: 10.3324/haematol.2017.164285. Epub 2017 Jun 28. PMID: 28659336; PMCID: PMC5622870.

19. Deepak P, Kim W, Paley MA, Yang M, Carvidi AB, El-Qunni AA, et al. Glucocorticoids and B cell depleting agents substantially impair immunogenicity of mRNA vaccines to SARS-CoV 2. https://www.medrxiv.org/content/10.1101/2021.04.05.21254656v2. 2021. 
20The LZTFL1 gene is a part of a transcriptional map covering $250 \mathrm{~kb}$ within the common eliminated region 1 (C3CER1) in 3p21.3. Kiss H, Kedra D, Kiss C, Kost-Alimova M, Yang Y, Klein G, Imreh S, Dumanski JP Genomics. 2001 Apr 1; 73(1):10-9

21-Tumor-suppressive functions of leucine zipper transcription factor-like 1 Wei Q, Zhou W, Wang W, Gao B, Wang L, Cao J, Liu ZP Cancer Res. 2010 Apr 1; 70(7):2942-50.

22-Wei Q, Zhou W, Wang W, Gao B, Wang L, Cao J, Liu ZP. Tumor-suppressive functions of leucine zipper transcription factor-like 1. Cancer Res. 2010 Apr 1;70(7):2942-50. doi: 10.1158/0008-5472.CAN-09-3826. Epub 2010 Mar 16. PMID: 20233871; PMCID: PMC2848875.

23-Wei, Q., Zhou, W., Wang, W., Gao, B., Wang, L., Cao, J., \& Liu, Z. P. (2010). Tumor-suppressive functions of leucine zipper transcription factor-like 1. Cancer research, 70(7), 2942-2950. https://doi.org/10.1158/0008-5472.CAN-09-3826

24-Exome sequencing identifies mutations in LZTFL1, a BBSome and smoothened trafficking regulator, in a family with Bardet-Biedl syndrome with situs inversus and insertional polydactyly.

Marion V, Stutzmann F, Gérard M, De Melo C, Schaefer E, Claussmann A, Hellé S, Delague V, Souied E, Barrey C, Verloes A, Stoetzel C, Dollfus H

J Med Genet. 2012 May; 49(5):317-21.

25-Wei Q, Gu YF, Zhang QJ, Yu H, Peng Y, Williams KW, Wang R, Yu K, Liu T, Liu ZP. Lztf11/BBS17 controls energy homeostasis by regulating the leptin signaling in the hypothalamic neurons. J Mol Cell Biol. 2018 Oct 1;10(5):402-410. doi: 10.1093/jmcb/mjy022. PMID: 30423168; PMCID: PMC7191877.

26-Datta, P., Allamargot, C., Hudson, J. S., Andersen, E. K., Bhattarai, S., Drack, A. V., et al. (2015). Accumulation of non-outer segment proteins in the outer segment underlies photoreceptor degeneration in Bardet-Biedl syndrome. Proc. Natl. Acad. Sci. U.S.A. 112, E4400-E4409. doi:

10.1073/pnas.1510111112

27-Jiang, J., Promchan, K., Jiang, H., Awasthi, P., Marshall, H., Harned, A., et al. (2016). Depletion of BBS protein LZTFL1 affects growth and causes retinal degeneration in mice. J. Genet. Genomics 43, 381391. doi: 10.1016/j.jgg.2015.11.006 
28-Wei, Q., Gu, Y. F., Zhang, Q. J., Yu, H., Peng, Y., Williams, K. W., et al. (2018). Lztfl1/BBS17 controls energy homeostasis by regulating the leptin signaling in the hypothalamic neurons. J. Mol. Cell Biol. 10, 402-410. doi: $10.1093 / \mathrm{jmcb} / \mathrm{mjy} 022$

29-Downes, D.J., Cross, A.R., Hua, P. et al. Identification of LZTFL1 as a candidate effector gene at a COVID-19 risk locus. Nat Genet 53, 1606-1615 (2021). https://doi.org/10.1038/s41588-021-00955-3

30-Jiang, H., Promchan, K., Lin, B. R., Lockett, S., Chen, D., Marshall, H., Badralmaa, Y., \& Natarajan, V. (2016). LZTFL1 Upregulated by All-Trans Retinoic Acid during CD4+ T Cell Activation Enhances IL-5 Production. Journal of immunology (Baltimore, Md. : 1950), 196(3), 1081-1090. https://doi.org/10.4049/jimmunol.1500719

31-Kang, S. G., Park, J., Cho, J. Y., Ulrich, B., \& Kim, C. H. (2011). Complementary roles of retinoic acid and TGF- $\beta 1$ in coordinated expression of mucosal integrins by T cells. Mucosal immunology, 4(1), 66-82. https://doi.org/10.1038/mi.2010.42

32-Direct and indirect effects of retinoic acid on human Th2 cytokine and chemokine expression by human T lymphocytes. Dawson HD, Collins G, Pyle R, Key M, Weeraratna A, Deep-Dixit V, Nadal CN, Taub DD BMC Immunol. 2006 Nov 21; 70:27

33-Woldemeskel BA, Garliss CC, Blankson JN. SARS-CoV-2 mRNA vaccines induce broad CD4+ T cell responses that recognize SARS-CoV-2 variants and HCoV-NL63. J Clin Invest. 2021 May 17;131(10):e149335. doi: 10.1172/JCI149335. PMID: 33822770; PMCID: PMC8121504.

34- Grifoni A, et al. Targets of T cell responses to SARS-CoV-2 coronavirus in humans with COVID-19 disease and unexposed individuals. Cell. 2020;181(7):1489-1501. doi: 10.1016/j.cell.2020.05.015.

35. et al. SARS-CoV-2-specific T cell immunity in cases of COVID-19 and SARS, and uninfected controls. Nature. 2020;584(7821):457-462. doi: 10.1038/s41586-020-2550-z

36. Mateus J, et al. Selective and cross-reactive SARS-CoV-2 T cell epitopes in unexposed humans. Science. 2020;370(6512):89-94. doi: 10.1126/science.abd3871.

37. Braun J, et al. SARS-CoV-2-reactive T cells in healthy donors and patients with COVID-19. Nature. 2020;587(7833):270-274. doi: 10.1038/s41586-020-2598-9. 
38. Woldemeskel BA, et al. Healthy donor T cell responses to common cold coronaviruses and SARS-CoV2. J Clin Invest. 2020;130(12):6631-6638. doi: 10.1172/JCI143120.

39. Nelde A, et al. SARS-CoV-2-derived peptides define heterologous and COVID-19-induced T cell recognition. Nat Immunol. 2021;22(1):74-85. doi: 10.1038/s41590-020-00808-x.

40. Bacher $P$, et al. Low-avidity CD4+ T cell responses to SARS-CoV-2 in unexposed individuals and humans with severe COVID-19. Immunity. 2020;53(6):1258-1271. doi: 10.1016/j.immuni.2020.11.016.

41. Richards KA, et al. Circulating CD4 T cells elicited by endemic coronaviruses display vast disparities in abundance and functional potential linked to both antigen specificity and age. J Infect Dis. doi: 10.1093/infdis/jiab076. [published online February 8, 2021].

42. Sekine T, et al. Robust T Cell Immunity in Convalescent Individuals with Asymptomatic or Mild COVID-19. Cell. 2020;183(1):158-168. doi: 10.1016/j.cell.2020.08.017.

43. Tan HX, et al. Adaptive immunity to human coronaviruses is widespread but low in magnitude. Clin Transl Immunology. 2021;10(3):e1264

44-COVID-19 vaccine BNT162b1 elicits human antibody and $\mathrm{T}<\mathrm{sub}>\mathrm{H}</$ sub $>1 \mathrm{~T}$ cell responses. Sahin $\mathrm{U}$, Muik A, Derhovanessian E, Vogler I, Kranz LM, Vormehr M, Baum A, Pascal K, Quandt J, Maurus D, Brachtendorf S, Lörks V, Sikorski J, Hilker R, Becker D, Eller AK, Grützner J, Boesler C, Rosenbaum C, Kühnle MC, Luxemburger U, Kemmer-Brück A, Langer D, Bexon M, Bolte S, Karikó K, Palanche T, Fischer B, Schultz A, Shi PY, Fontes-Garfias C, Perez JL, Swanson KA, Loschko J, Scully IL, Cutler M, Kalina W, Kyratsous CA, Cooper D, Dormitzer PR, Jansen KU, Türeci Ö Nature. 2020 Oct; 586(7830):594-599

45-An mRNA Vaccine against SARS-CoV-2 - Preliminary Report. Jackson LA, Anderson EJ, Rouphael NG, Roberts PC, Makhene M, Coler RN, McCullough MP, Chappell JD, Denison MR, Stevens LJ, Pruijssers AJ, McDermott A, Flach B, Doria-Rose NA, Corbett KS, Morabito KM, O'Dell S, Schmidt SD, Swanson PA 2nd, Padilla M, Mascola JR, Neuzil KM, Bennett H, Sun W, Peters E, Makowski M, Albert J, Cross K, Buchanan W, Pikaart-Tautges R, Ledgerwood JE, Graham BS, Beigel JH, mRNA-1273 Study Group. N Engl J Med. 2020 Nov 12; 383(20):1920-1931.

. 46-Hall JA, Cannons JL, Grainger JR, Dos Santos LM, Hand TW, Naik S, Wohlfert EA, Chou DB, Oldenhove G, Robinson M, Grigg ME, Kastenmayer R, Schwartzberg PL, Belkaid Y. Essential role for retinoic acid in the promotion of CD4(+) T cell effector responses via retinoic acid receptor alpha. Immunity. 2011;34:435-447.

47-Hall JA, Grainger JR, Spencer SP, Belkaid Y. The role of retinoic acid in tolerance and immunity. Immunity. 2011;35:13-22 
48-Iwata M, Hirakiyama A, Eshima Y, Kagechika H, Kato C, Song SY. Retinoic acid imprints gut-homing specificity on T cells. Immunity. 2004;21:527-538

49- Elias KM, Laurence A, Davidson TS, Stephens G, Kanno Y, Shevach EM, O'Shea JJ. Retinoic acid inhibits Th17 polarization and enhances FoxP3 expression through a Stat-3/Stat- 5 independent signaling pathway. Blood. 2008;111:1013-1020.

50-Mucida D, Park Y, Kim G, Turovskaya O, Scott I, Kronenberg M, Cheroutre H. Reciprocal TH17 and regulatory T cell differentiation mediated by retinoic acid. Science. 2007;317:256-260.

51- Iwata M, Eshima Y, Kagechika H. Retinoic acids exert direct effects on T cells to suppress Th1 development and enhance Th2 development via retinoic acid receptors. Int Immunol. 2003;15:10171025.

52-Retinoic acid imprints gut-homing specificity on T cells Iwata M, Hirakiyama A, Eshima Y, Kagechika H, Kato C, Song S Immunity. 2004 Oct; 21(4):527-38.

53-Generation of gut-homing IgA-secreting B cells by intestinal dendritic cells.Mora JR, Iwata M, Eksteen B, Song SY, Junt T, Senman B, Otipoby KL, Yokota A, Takeuchi H, Ricciardi-Castagnoli P, Rajewsky K, Adams DH, von Andrian UH Science. 2006 Nov 17; 314(5802):1157-60.

54-Hall, J. A., Cannons, J. L., Grainger, J. R., Dos Santos, L. M., Hand, T. W., Naik, S., Wohlfert, E. A., Chou, D. B., Oldenhove, G., Robinson, M., Grigg, M. E., Kastenmayer, R., Schwartzberg, P. L., \& Belkaid, Y. (2011). Essential role for retinoic acid in the promotion of CD4(+) T cell effector responses via retinoic acid receptor alpha. Immunity, 34(3), 435-447. https://doi.org/10.1016/j.immuni.2011.03.003

55-Elizondo G, Corchero J, Sterneck E, Gonzalez FJ. Feedback inhibition of the retinaldehyde dehydrogenase gene ALDH1 by retinoic acid through retinoic acid receptor alpha and CCAAT/enhancerbinding protein beta. J Biol Chem. 2000 Dec 15;275(50):39747-53. doi: 10.1074/jbc.M004987200. PMID: 10995752.

56-Schwarz, E J et al. "Retinoic acid blocks adipogenesis by inhibiting C/EBPbeta-mediated transcription." Molecular and cellular biology vol. 17,3 (1997): 1552-61. doi:10.1128/MCB.17.3.1552 
57-Marchildon F, St-Louis C, Akter R, Roodman V, Wiper-Bergeron NL. Transcription factor Smad3 is required for the inhibition of adipogenesis by retinoic acid. J Biol Chem. 2010 Apr 23;285(17):13274-84. doi: 10.1074/jbc.M109.054536. Epub 2010 Feb 23. PMID: 20179325; PMCID: PMC2857127.

58-Morita T, Miyakawa K, Jeremiah SS, Yamaoka Y, Sada M, Kuniyoshi T, Yang J, Kimura H, Ryo A. AllTrans Retinoic Acid Exhibits Antiviral Effect against SARS-CoV-2 by Inhibiting 3CLpro Activity. Viruses. 2021 Aug 23;13(8):1669. doi: 10.3390/v13081669. PMID: 34452533; PMCID: PMC8402917.

59-Donnarumma M, Nocerino M, Lauro W, Annunziata MC, Marasca C, Fabbrocini G. Isotretinoin in acne treatment during the coronavirus disease 2019 (COVID-19): A retrospective analysis of adherence to therapy and side effects. Dermatol Ther. 2021;34(1):e14677. 10.1111/dth.14677

60-Gundogdu M, Dere G. Is systemic isotretinoin use a risk factor for coronavirus disease 2019 (COVID19)? J Cosmet Dermatol. 2021;20(6):1568-1570. 10.1111/jocd.14044

61-Seo GY, Jang YS, Kim HA, Lee MR, Park MH, Park SR, Lee JM, Choe J, Kim PH. Retinoic acid, acting as a highly specific IgA isotype switch factor, cooperates with TGF- $\beta 1$ to enhance the overall IgA response. J Leukoc Biol. 2013 Aug;94(2):325-35. doi: 10.1189/jlb.0313128. Epub 2013 Jun 6. PMID: 23744644.

62-Uehara S, Grinberg A, Farber JM, Love PE. A role for CCR9 in T lymphocyte development and migration. J Immunol. 2002 Mar 15;168(6):2811-9. doi: 10.4049/jimmunol.168.6.2811. PMID: 11884450.

63-Cosorich I, McGuire HM, Warren J, Danta M, King C. CCR9 Expressing T Helper and T Follicular Helper Cells Exhibit Site-Specific Identities During Inflammatory Disease. Front Immunol. 2019 Jan 4;9:2899. doi: 10.3389/fimmu.2018.02899. PMID: 30662436; PMCID: PMC6329311.

64-Gauldie, J., Kolb, M., Ask, K., Martin, G., Bonniaud, P., \& Warburton, D. (2006). Smad3 signaling involved in pulmonary fibrosis and emphysema. Proceedings of the American Thoracic Society, 3(8), 696-702. https://doi.org/10.1513/pats.200605-125SF

65-Aguet, F. et al. The GTEx Consortium atlas of genetic regulatory effects across human tissues. Science $369,1318-1330(2020)$. 
66-Dunham, I. et al. An integrated encyclopedia of DNA elements in the human genome. Nature $489,57-$ 74 (2012). 